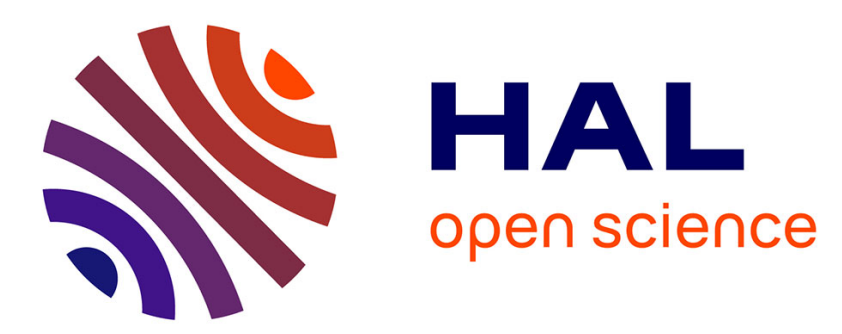

\title{
About the use of "trailing echoes" for the detection of disbond at solid-solid interface
}

M. de Billy, L. Adler, G. Quentin

\section{To cite this version:}

M. de Billy, L. Adler, G. Quentin. About the use of "trailing echoes" for the detection of disbond at solid-solid interface. Journal de Physique IV Proceedings, 1994, 04 (C5), pp.C5-917-C5-920. 10.1051/jp4:19945201 . jpa-00252885

\section{HAL Id: jpa-00252885 https://hal.science/jpa-00252885}

Submitted on 1 Jan 1994

HAL is a multi-disciplinary open access archive for the deposit and dissemination of scientific research documents, whether they are published or not. The documents may come from teaching and research institutions in France or abroad, or from public or private research centers.
L'archive ouverte pluridisciplinaire HAL, est destinée au dépôt et à la diffusion de documents scientifiques de niveau recherche, publiés ou non, émanant des établissements d'enseignement et de recherche français ou étrangers, des laboratoires publics ou privés. 


\title{
About the use of "trailing echoes" for the detection of disbond at solid-solid interface
}

\author{
M. DE BILLY, L. ADLER ${ }^{(1)}$ and G. QUENTIN
}

Groupe de Physique des Solides, Universités Paris 6 et 7, Tour 23, 2 Place Jussieu, 75251 Paris cedex 05, France

\begin{abstract}
In a recent past C.K. Jen et al. have shown $[1,2]$ that "spurious echoes" caused by diffraction effects and finite rod radius may exist in a bar, when it is axially insonified. In this paper, the phenomenon is further investigated and the use of these echoes for investigation of bond quality between two materials is suggested.

Résumé

Récemment C.K. Jen et al. [1,2] ont montré l'existence d'échos dus aux effets de diffraction et aux dimensions finies dans le cas d'échantillons, tels que des barreaux cylindrique, excités à l'une de leur extrémités selon une direction parallèle à leur axe. Nous proposons de décrire ici comment ces échos peuvent être utilisés à des fins de controle non-destructif.
\end{abstract}

\section{Introduction}

It was shown by C.K. Jen et al. [1,2] that trailing echoes [3] exist on rods acoustically insonified along their axis by compressional waves Different techniques have been suggested and developped to eliminate these unwanted echoes which may interfere with the signals which correspond to the direct propagation of the wave in the rod. In case of rods immersed in air, it was found that the more efficient procedure to reduce the amplitude of these echoes which result from reflexion and mode conversion at the air-material boundary is to use tapered samples or notched boundary surfaces. As the amplitude of the trailing echoes depends on the boundary conditions between the external medium and the rod, that suggests to use these echoes for qualifying the boundary. This paper has two objectives. The first one consists of studying the influence of the frequency and the cross section of the target on the time records. As a second objective, we analyse the possibility to use these specific echoes to control the bound interface between two elastic medium.

\section{Experimental results}

\subsection{Experimental conditions}

The experiments are carried out on bars of $2 \mathrm{~cm}$ length having various shapes of the cross section (square, circular, hexagonal and rectangular). The ultrasonic excitation and detection are performed with commercial longitudinal broad-band contact transducers of $6.3 \mathrm{~mm}$ in diameter. The

(1) Permanent address: Ohio State University, Welding Engineering Dept., 190 West, 19th avenue, Columbus, Ohio, U.S.A. 
emitter and the receiver are glued at the two ends of the samples (See Fig.1). Measurements were performed at different frequencies on duraluminum, brass and stainless-steel rods. The transmitted echoes recorded by the receiver present characteristics structure which includes the direct echo (A) and a series of echoes which result from mode conversion at the interface air-metal. The echo (B) provided from the multiple reflexion by the extremities of the bar. This structure is illustrated in figure 2 where the transmitted time-domain signals are plotted for a brass cylindrical rod of $8 \mathrm{~mm}$ diameter at two different frequencies (Fig 2-a $: F=3.5 \mathrm{MHz}$; Fig. 2-b $: F=7.0 \mathrm{MHz}$ ).



Fig. 1 Geometry of the set-up.
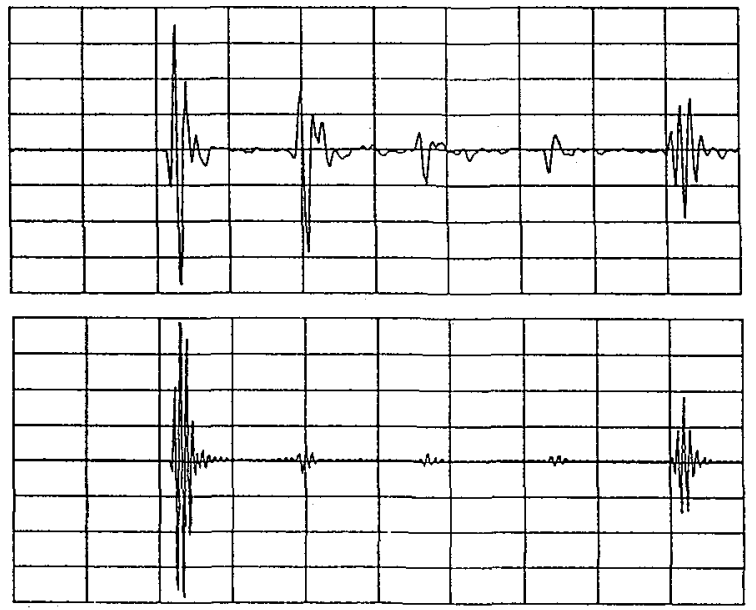

T/div 2 js

Fig.2 Transmitted time domain signals for a brass cylindrical rod :

$\mathrm{a} / \mathrm{F}=3.5 \mathrm{Mhz}$

$\mathrm{b} / \mathrm{F}=7.0 \mathrm{Mhz}$

\subsection{Influence of the frequency}

The results obtained on the same cylindrical rod at different frequencies are given in figure 2 . We notice similar echographic sequences in time domain : the positions of the different echoes do not change with the frequency. Additional observations can be made e.g. the amplitude of te trailing echoes decreases with distance and the attenuation of the higher frequency components indicate dispersive behavior.

\subsection{Influence of the diameter}

Measurements are obtained on rods of circular cross-section with different diameters ranging from 2 to $18 \mathrm{~mm}$ (Fig. 3). It was noticed that the echo which goes through directly, increases until the diameter of the rod is of the same order of magnitude that the diameter of the emitter. For rod diameters which are larger than the transducer diameter the amlpitude of the first echo remains constant. We verified also that the echo positions in the time domain increases linearly with the diameter. This result agrees with the Redwood calculations [3]. 



T/div 2 us

Fig. 3 Influence of the diameter of the rod on echographic structure $(a: d=2 \mathrm{~mm} ; b: d=8 \mathrm{~mm} ; c$ $: d=14 \mathrm{~mm} ; \mathrm{d} ; \mathrm{d}=18 \mathrm{~mm})$

\subsection{Influence of the cross-section shape}

Experiments were also carried out at the same frequency on brass samples having different shapes of the cross-section. The results are given in figure 4 . Alhough we notice an increase of the "noise" into the echographic structure recorded for a hexagonal cross-section, an examination of the time signals reveals that the structures are very similar. This is justified if we consider that for any sample, the reflction and the mode conversions are identical in the cross section parallel to the direction of propagation (Fig.5).

\section{Boundary interface control}

The experiments described in the previous section were realized firste with samples immersed in air.Because of the reflexion and mode conversion at the boundary between the rod and air, it was verified that spurious echoes exist, the amplitudes of which are characteristic of the bound. This is illustrated in figure 6 where time-domain signals are redrawn, obtained through a finite graphite rod immersed either in air (Fig.6-a) or in a tin-lead. matrix (Fig.6-b and c). The difference that we observed between the two last drawings results from the nature of the bond : the time signals represented in figure 6-b are respectively characteristic of a bad bond and a good bond.

In the two last figures, we observe a signal which corresponds to the direct propagation of the longitudinal wave through the surrounding medium. These echoes are observed because the diameter of the rod is smaller than the dimension of the active transducer. For the case of good contact between the two materials, energy is transmitted to the external material and the trailing echoe disappears as can be seen on figure 6 -c.

\section{Conclusion}

The use of trailing echoes propagating in rod of various shapes can be used to detect disbonds at solid-solid interface. This experimental technique should be limited to small rod in diameter and in length. 
<smiles>CC(C)C=CC1CCCC1</smiles>
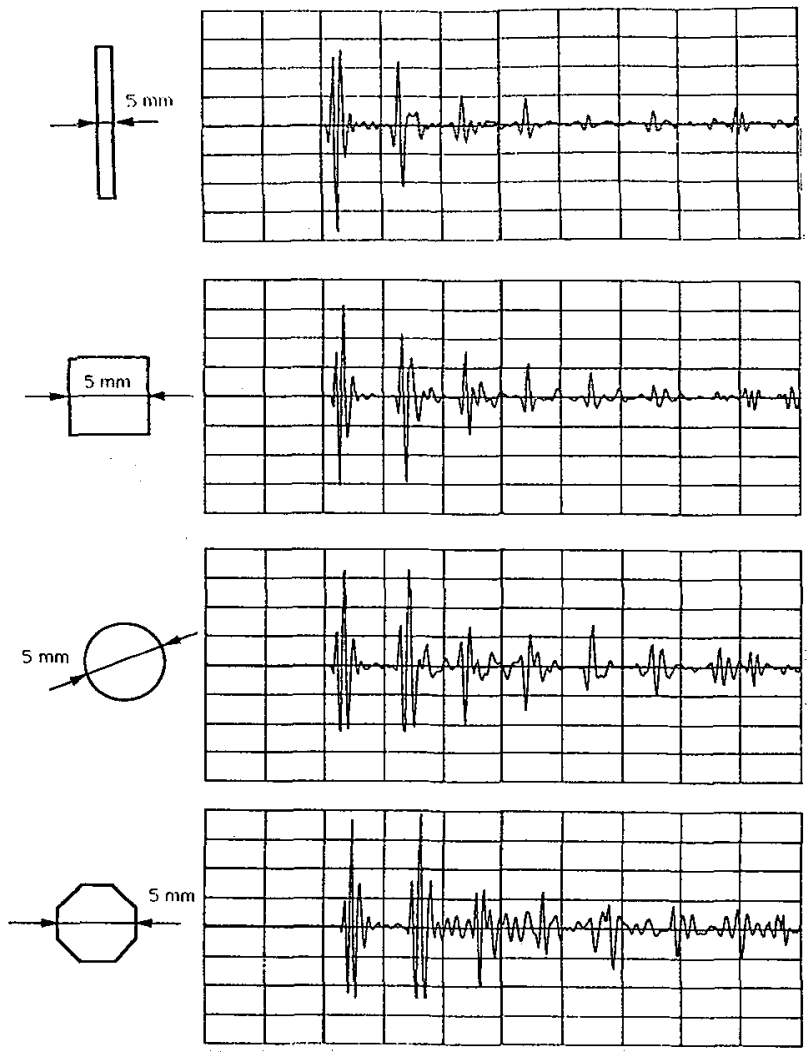

T/div $2 \mu s$

Fig.4 Influence of the shape of the cross-section

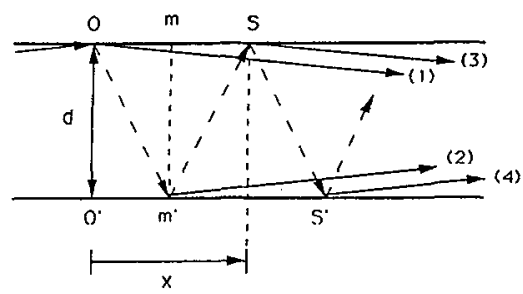

Fig. 5 Cross-section parallel to the direction of propagation


T/div . 5 us

Fig.6 Influence of the quality of the bound on the time domain-signals. a Sample in air

b/ Sample in tin-lead matrix (case of a bad bound) c/ Sample in tin-lead matrix (case of a good bond)

\section{References}

[1] C.K. Jen, L. Piche and J.F. Bussière J. Acoust. Soc. Am. 88, 23-25 (1990).

[2] C.K. Jen, A. Safaai-Jazi, J.C.H. Yu, C. Neron, G. Perluzzo and Z. Wang, Review of Progress in QNDE, Vol. 10A, edited by D.O. Thompson and D.E. Chimenti, 867-874 (1990).

[3] M. Redwood, Mechanical Waveguides Pergamon, N.Y. (1960), Chap. 9.

This work has been supported by NATO Scientific Affairs Division under Grants \# CR691057 